\title{
Research methods for computer applications
}

\author{
JO W. TOMBAUGH \\ Carleton University, Ottawa KIS SB6, Canada
}

\begin{abstract}
This paper identifies issues and techniques useful to psychologists interested in applied research for computer applications. Applied research includes guideline research, product development evaluation, and field trial evaluation. Suggestions for improved guideline research involve screening the problem to determine its potential usefulness and screening the design to make sure it involves sufficiently representative tasks, subjects, and materials for the desired generality. Product development evaluation requires techniques for testing users that are fast, flexible, and inexpensive, such as "user trials" of products in ergonomics and "user edits" for testing documentation. Field trials of office automation or videotex systems lead to decisions about further introduction of those systems. A methodology for planning the research component of field trials, "evaluation assessment," provides a set of steps to use in deciding which design and measures should be collected.
\end{abstract}

Psychologists can serve as professional communicators who summarize and interpret relevant psychological literature for system designers (Macdonald-Ross, 1978). They can also contribute both conceptual and empirical methods to the area (Barnard, Hammond, Morton, Long, \& Clark, 1981). Conceptual tools are analytic methods developed to help system designers make appropriate design decisions (e.g., Moran, 1981b). Empirical methods, the focus of this paper, are those that involve data collection in the process of dealing with computer applications.

Three types of applied research are covered in this article: guideline, product development, and evaluation research. Guideline research tends to be centered in universities or in human-factors research laboratories financed by government and large manufacturers. It is similar to traditional psychological research, even though the strategies that lead to the development of useful guidelines are not well understood (Barnard et al., 1981; Moher \& Schneider, 1982).

With product development and evaluation research, psychologists must find workable solutions to specific problems rather than discover general principles. Questions are concerned with whether (as opposed to why) a particular procedure works. The controlled experiment is often inadequate and inappropriate for this type of research. Instead, methods are needed for gathering empirical evidence on such questions quickly and efficiently. Product testing methods in ergonomics (Rennie, 1981) and education (Sanders \& Cunningham, 1973), as well as requirements analysis methods for computer systems (Ramsey \& Atwood, 1979), are particularly useful. Sending a psychologist into an applied research setting with knowledge of only tradi-

This research was supported by a grant from the National Science and Engineering Research Council of Canada (Strategic Grant G0365). tional experimental designs is comparable to sending a carpenter to build a house with only a hammer and saw.

The third type of applied research is evaluation research. Major computer systems are typically tested in field trials before being widely implemented. Information gathered in these tests ranges from questions of equipment reliability, to user satisfaction, to measuring changes in user activity and productivity. An awareness of the difficulties in field research (Cook \& Campbell, 1979; Rutman, 1980) is important to these kinds of endeavors. Methodological considerations associated with each of these three approaches are considered in turn.

\section{APPROACHES TO DEVELOPING GUIDELINES}

Ideally, guidelines research will lead to general principles that aid system designers. As Moran (1981a, p. 5) has stated, "An applied psychology of the user, like any applied science, is first of all a science. This means that it not only collects data, but also attempts to formulate theories to explain the data . ... Its role is to provide the designer with a systematic way of thinking about user behavior and methods for dealing with it."

A number of writers in this area (Barnard et al., 1981; Moher \& Schneider, 1982; Moran, 1981a; Ramsey \& Atwood, 1979) have stressed the need to develop research techniques that lead to the development of useful theories and guidelines. "Although the literature contains numerous references to the use of experimental methods, there are few references on investigations into the methodology itself' (Moher \& Schneider, 1982, p. 67). Recent reviews in a number of applied areastypography (Macdonald-Ross, 1978), technical writing (Anderson, 1980; Wright, 1978), learning from text (McConkie, 1978)-also consider the methodologies employed to answer practical questions in these applied 
fields to be inadequate. Laboratory research concerning a single variable, using simplified stimulus material and simplified performance criteria, are often encountered. The question addressed is often "competitive" (e.g., Are menu-driven systems better than command-driven systems?) instead of "conditional" (e.g., Under what conditions is a menu-driven system better than a commanddriven system?). Overly simplified research of this type lacks credibility because of the lack of generality of the results and the failure to provide information about interactions.

To encourage conditional questions and to avoid the difficulties of single-variable research, many writers suggest using a systems or framework approach in which the characteristics of user, task, performance measures, and other situational factors are considered jointly (e.g., Benbasat, Dexter, \& Masulis, 1981). The difficulty with this approach is that it always identifies more potential interacting variables than can be manipulated in a single study, or even a single research program. As noted by Barnard et al. (1981, p. 89), "any ergonomic approach which attempts to formulate guidelines or design principles on the basis of highly selective parametric studies is likely to have inherent limitations." Thus, there are two challenges for the applied researcher: (1) deciding what variables to manipulate and measure (selecting the problem), and (2) insuring that the results are sufficiently general to be useful to practitioners (designing the experiment).

\section{Selecting the Problem}

An applied researcher is motivated in part by a desire for his results to be directly useful (Marx \& Hillix, 1963). Thus, the problem to be studied must be selected with care. Advice found in the literature focuses on the origin of the problem. Problem sources include theory, user errors, user/computer incompatibility, expertpractitioner, and naturalistic observation, as described below.

Theory. Moran (1981a) has suggested that theory should guide the formation of problems. Decisions concerning variables to study and measure are based on the theory. Card, Moran, and Newell (1980, p. 33) express this approach well: "Our motives for studying the manuscript-editing task are both to extend the theory of man as a symbolic information processing system and to apply the theory of human information processing in practical task domains. The consideration of tasks with real application is important as a check on the often-noted tendency for psychological research to become paradigm-bound, as a way of testing the power of theoretical ideas against the complexity of real-world behavior, and as a means of fostering progress in the application domain." The work by Mayer (e.g., Mayer, 1981) on teaching computer programming and by Sebrechts, Deck, and Black (1983) on manuals for word processing are excellent examples of this approach.
User errors. Chapanis (1965) suggests the use of the critical incident technique, with case studies of particularly poor and good implementations to identify or determine the important factors. Similarly, Norman (1982) analyzes performance errors to derive system design rules. For example, "mode errors" suggest a need for improved system feedback to the users.

User/computer incompatibility. Barnard et al. (1981) state that identified cognitive incompatibilities between human users and computers are a valid source of research ideas. Since one such incompatibility is less flexibility in understanding input by the computer than by the human operator, they choose to study dialogue to develop optimal ways of narrowing this gap.

Expert-practitioner. Anderson (1980) and McdonaldRoss (1978) suggest that research should focus on the intuitions of skilled and experienced practitioners, such as successful system designers.

Naturalistic observation. McConkie (1978) argues that empirical. descriptive studies of how the potential end users naturally process information should be the starting point for research.

The problem sources listed above would appear to be determined to a large extent by the experiences and backgrounds of the researchers. All have been used successfully by the investigators who recommend them. Yet using one of these methods as a starting point for problem formation is certainly not sufficient to guarantee utility. The appropriateness of the problem, not its origin, will ultimately determine its applicability. Consequently, criteria for screening a selected problem for appropriateness are needed. Tombaugh and Dillon (Note 1) developed three research criteria after a first effort at guideline research failed. This experiment will be briefly described, followed by an explanation of the criteria and the manner in which the study failed to meet them.

The origin of the experiment resulted from observation of a design flaw in an early prototype of a videotex system. User input was not echoed on the display screen. A field experiment was performed to demonstrate to system designers the importance of feedback (echoed input) for new videotex users. Amount of delay and presence/absence of feedback were manipu. lated: Delay was incorporated because absence of feedback was expected to cause inappropriate responding under longer delays. Analysis of the results supported this prediction, but it was not particularly useful. System designers already knew that keypresses should be echoed; lack of feedback was a minor problem compared to some others for the users. So, the experiment made no contribution to psychological theory.

The screening criteria developed after this experiment were generalizations of the three problems briefly stated above. Problems should be screened for their reality to users, utility to designers, and contribution to psychological theory. First, reality to users should be 
assessed by asking whether the experimental problem is truly a problem to the user. This is particularly relevant when the researcher has had little or no contact with the user group or the computer application selected for study. An hour or 2 of observation can often focus the problem. The feedback experiment failed this test because the new users worked so slowly with the system that only delays longer than the system naturally provided resulted in increased responding during delay. In fact, users had many difficulties that influenced performance much more than lack of feedback. Watching a few new users on the system before designing the experiment would have led to a reformulation of the problem.

Utility is a criterion that focuses on whether the results will be useful to designers. This is very difficult for the researcher to assess. Observation of a design flaw, such as failure to provide feedback, is not sufficient evidence. The reason for the existence of the flaw must also be considered. Whenever existing guidelines and common practice show that most designers would recognize an observed flaw as bad practice, the experiment will not be very useful. For the feedback experiment given above, this was the greatest miscalculation. The signs that should have been noted before deciding to conduct the experiment were as follows: (1) It is rare to find a computer system in which user responses are not echoed, and (2) no designer would argue that feedback is undesirable. In fact, before the experiment was completed, a new prototype of the videotex system was released that provided user feedback. The early prototype had omitted that feature because of implementation problems and time constraints, not inappropriate design.

Finally, the theory criterion is concerned with whether the study will advance understanding of cognitive processes. If it does, it will stand on its own merit as a contribution to the psychological literature, whether or not it is useful to designers. The videotex experiment failed this test because it had no manipulations designed to increase understanding of feedback mechanisms. It utilized, but did not expand, knowledge of psychological principles. Thus, a retrospective examination of the experiment using the criteria based on users, designers, and theory indicates that the experiment should not have been attempted.

\section{Designing the Experiment}

Even when the problem addressed in guideline research is of interest to designers, there is a possibility that the experimental findings will not have wide application. Design and implementation decisions can limit the usefulness of the results. How to make research sufficiently general to be credible for the applied setting is not well understood. Barnard et al. (1981, p. 90) call for "an integration of different types of empirical evidence and different analytic methods." This approach is called "triangulation" by Denzin (1978) and is used to increase the credibility of research findings. The ration- ale for this approach is that different methodological approaches (e.g., naturalistic observation and controlled experimentation) and different types of data (e.g., verbal reports and performance measures) have different strengths and weaknesses, thus complementing each other when used jointly (Ericsson \& Simon, 1980; Patton, 1980).

Moher and Schneider (1982) note that task selection and subject selection need to be carefully considered. The task or tasks used in the research should approach the complexity of those tasks to which the research is to be generalized. It should not be overly simplified. Comparison of computer-initiated dialogue (e.g., menu selection) and user-initiated dialogue (e.g., command language) using a task with only three commands will not be satisfactory. In addition, subject selection based on who is available should be replaced by selection from the population or populations of interest. If the subjects available are computer novices and the research question sensibly concerns experts, the outcome will not have general interest.

Finally, important extraneous variables should be identified and controlled in a manner that will not limit generality of the results. More use of control by randomization or by systematic variation rather than control by holding constant may sometimes be effective. As an example, assume that research is to be conducted to compare two different ways of preparing user manuals (e.g., structured format vs. narrative). If a single version is prepared for each method (identical except for structure), a finding in favor of one type of manual might be a special case. However, if different manuals are produced in both structured and narrative form and one form is generally superior, the results will be taken much more seriously.

Choice of task, subjects, and materials affect the validity of the research design (Campbell \& Stanley, 1963). Traditional psychological research emphasizes internal validity. the extent to which a relationship between two variables is shown to be causal. To be taken seriously by practitioners, researchers must attempt to increase the external validity of their designs, the extent to which the results generalize to other settings, persons, and operations. The challenge is to increase external validity without a corresponding sacrifice of internal validity.

\section{PRODUCT DEVELOPMENT EVALUATION}

It is time for psychologists to assume a greater role in the production, implementation, and evaluation of computer systems. There is increased awareness that computer systems designed for naive and discretionary users will not be successful unless they are reasonably easy to learn and use. As a result, there are increasing demands that usability criteria for computer systems be established by designers in the same manner that performance criteria are now established for the system itself. In addition to specifying minimum response time 
and minimum down time, the maximum training time and the acceptable error rate for the intended users may soon be specified (Bennett, 1979). Software tools are being developed to separate the task of diaglogue design from the actual design of a system's functions (Feldman \& Rogers, 1982; Roach, Hartson, Ehrich, Yunten, \& Johnson, 1982). Thus, a "dialogue specialist" with little understanding of the technical specifications of the system can work on developing, testing, and improving the interface between user and system independently of the programmers and designers. The shortage of experienced computer scientists and engineers dictates that their talents should be concentrated on tasks for which they are trained. The design of equipment and software must be their major concern.

The methodologies needed for product testing are considerably different from those needed for guideline research. Instead of emphasizing carefully controlled experimentation to determine causal variables and their interaction, the empirical work should be designed to find out whether or not users are able to use the prototype as intended, and if not, to identify the revisions that need to be made. It is imperative that the methods be fast, flexible, and inexpensive.

A confusion between the type of research required to provide guidelines and the type needed to test a prototype has led psychologists given an opportunity to participate in product evaluation to undertake research that is too slow and limited for the development process. For example, Wagner (1980), who is in charge of producing manuals for IBM, rejects testing their manuals with users because of the methods he has observed: "The typical test is very specific and geared to a very small part of a manual . . . . It is not cost-effective to test more than a small percent of the manual .... Statistically significant test scores require too many test subjects" (p. 99).

Because the need for systematic and efficient methods of obtaining user feedback is great, there is a growing emphasis upon developing appropriate methodologies. For example, some researchers are developing systematic methods for testing manuals and other forms of instructions. Winbush and McDowell (1980) describe a systematic approach based on the use of a test coordinator, an individual charged with assessing the usability of manuals. This highly structured approach involves three parts: (1) manual reading, in which subjects first identify sections they find difficult and then take a written test on the document content, (2) procedural testing, in which subjects attempt to actually perform tasks described in the manual in a simulated environment, and (3) attitudinal questionnaire administration to determine the degree to which users find the manual to be satisfactory.

Less quantitative and structured methods, which take less time and may be equally effective, are also available for testing computer systems. For example, Atlas (1981) defines a "user edit" in the following manner: "The user edit is based on a very simple idea: Find someone who knows nothing about your machine and have him work with it, using only your manual as a guide; his errors and hesitations should tell you where the weak points are. To get more detailed information, it is also a good idea to ask users to talk while they work, telling what they are trying to do, what they are looking for, what gives them trouble, and what they suggest to make the manual better" (p. 28). Testing takes place with a very small number of users. Often, modifications are suggested after testing only one or two users. These methods are gaining increased recognition as being practical in the time required for system development and for leading to improvement in systems. Buxton and Sniderman (1980) refer to the process of test/modify/test as design interation. It is similar to the "user trial" proposed for product evaluation in ergonomics (Johnson \& Baker, 1974; Rennie, 1981; Thompson \& Rath, 1974).

Two methodological notes should be kept in mind in product development evaluation. First, Marcel and Barnard (1979) report that there are major differences in the reading patterns of subjects asked to explain what instructions meant without using the machine (or a simulated version) and those who actually tried to use it. The first group systematically read through the instructions. The second group tended not to use the instructions in order but to jump around, and these users often tried things on the machine without referring to the instructions. Lewis and Mack (1982) noted a similar problem with secretaries using a tutorial for a word processor. They tended to jump around in the manual, even though it had a carefully planned order. Early testing is valuable to alert designers that a particular dialogue or manual is too complex for the user, but finding that users are able to follow the instructions in this form does not guarantee that they will follow them properly when actually using a system. Thus, to get an accurate impression of how a manual will be used, testing should also involve actual interaction with the machine as soon as possible. There is a growing emphasis by designers on having the equipment and solftware available to design inexpensive and easily modified prototypes (Green, 1982).

Second, Dillon and Tombaugh (1982) note that user testing in a laboratory environment was excellent for insuring that users could follow the instructions. However, a test in the actual environment in which the device was to be used showed that the intended users (who had expressed satisfaction in the laboratory) did not like the material when it was presented in the field. Thus, it may be that user tests to measure user satisfaction will require testing in the user's natural environment (i.e., field trials). This does not mean that the 
laboratory work on clarity should be abandoned. Arndt (1977) notes the limitations of laboratory testing but sees them as needed preliminary work before testing in a naturalistic setting can be started. The field trial that starts with a system that can be used but is not particularly well liked can more easily be modified to a user's satisfaction than one that is not understandable to the user at the time it is introduced in the field.

In summary, techniques are being developed to insure that computer prototypes are usable by the group for whom they are intended. These techniques can be employed with minimum time and effort. However, there are few data indicating whether findings from user trials are generally reliable or highly dependent on intuitions and perceptiveness of an experienced researcher. As noted by Rennie (1981, p. 163), "overall there have been comparatively few papers published on consumer product evaluation. One reason for this may be that although ergonomics studies are being conducted in the area, few researchers feel their work would be of general interest and may feel their methods would not stand up to rigorous scientific examination." However, as qualitative evaluation methods gain in rigor (Patton, 1980) and as videotape and tape recorders increase the accuracy of observation, it should be possible to gain a direct estimate of the reliability and validity of the data collected.

\section{FIELD EVALUATION}

There is a growing emphasis upon evaluation of field trials when new technical products are introduced into a working environment. For example, the Canadian Department of Communications is organizing multimillion dollar field trials of integrated office equipment to evaluate the impact of the equipment upon a variety of outcome measures. In addition, field trials involving videotex systems are being conducted in a variety of locations (e.g., Aldrich, 1982).

Although the term "evaluation" is applied to this type of methodology, as well as to that presented in the last section, there are important differences in the two types of research. The distinction is similar to that between formative and summative evaluation in the literature on social program evaluation (e.g., Rutman, 1980). Formative evaluation is research in service of an application. Data are collected to improve the service. For example, the user edit is used to improve a document. Summative evaluation is research in judgment of an application. A decision on whether or not to introduce office automation in other offices might depend on the outcome of a field trial. The preferred research method for summative evaluation is the true experiment, applied in a field study. This is difficult research to do well. The pioneering methodological paper of Campbell and Stanley (1963) has more recently been considerably expanded and updated by Cook and Campbell (1979) and represents the type of research called for in field trials. A knowledge of experimental and quasiexperimental designs and statistical treatment of quasiexperimental designs is of great benefit to those interested in evaluation of the introduction of new systems. For example, if routine records of an office keep track of number of dollars earned on a monthly basis, analysis of the interrupted time-series design (Cook \& Campbell, 1979) will indicate whether the introduction of office automation changed either the level or the rate of growth in the earnings.

Evaluation assessment is another methodology that is of great value to the researcher involved in planning the evaluation of a field trial (Rutman, 1980; Wholey, 1977). Policy makers often state the expected outcomes of a new program in vague and general terms; "greater productivity" and "a better working environment" are typical examples. Unless the researcher can find acceptable operational definitions for such terms, the evaluation will not be effective. Evaluation assessment provides a list of steps for the researcher to follow in deciding on measures and the experimental design. For example, documents about the application (e.g., promotional material, requirement specifications, minutes of meetings) are used to develop a "rhetorical application model" that lists the various components of the application and their intended effects. For example, an office system might include a management information system to improve the quality of decision making, a messaging system to improve office communication, and a word processing system to increase productivity. The researcher will then interview the policy makers to find out if all of the components and effects of interest are identified and to attempt to determine measures for the expected effects. The interviews might lead the researcher and policy maker to agree that "improved office communication" will be represented by increased use of memos between managers and staff and by decreased union grievances. Typically, no measure is found for some effects and they are eliminated from the research design. For example, "improved quality of decision making" might fall into this category. The final experimental design is then determined, based upon the defined measures and the availability of appropriate control groups. While utilization of evaluation assessment procedures does not eliminate the possibility of poorly utilized evaluation, it does insure that the researcher is well acquainted with the application and increases the communication between researcher and policy makers.

In summary, psychologists working in applied research on the development of computer systems may be called upon to participate in a large variety of data collection activities for different reasons and with different criteria for success. Exposure to the traditional methods of human-factors research, to field research techniques, and 
to formative research techniques will provide the flexibility the psychologist needs to select the appropriate tools for each type of research task.

\section{REFERENCE NOTE}

1. Tombaugh, J. W., \& Dillon, R. A. A field experiment with a videotex system. Unpublished manuscript, Carleton University, 1979.

\section{REFERENCES}

Aldrich, M. J. World review of private videotex. Proceedings of Videotex '82. Middlesex, England: Online, Ltd., 1982.

Anderson, P. V. The need for better research in technical communication. Journal of Technical Writing and Communication, $1980,10,271-282$.

ARNDT, J. Laboratory studies and the laboratory paradigm of man: Confessions of an uneasy consumer researcher. Journal of Consumer Policy, 1977, 1, 9-12.

AtLAS, M. A. The user edit: Making manuals easier to use. IEEE Transactions on Professional Communication, 1981, PC-24, 28-29.

Barnard, P. J., Hammond, N. V., Morton, J., Long, J. B., \& Clark, I. A. Consistency and compatibility in human-computer dialogue. International Journal of Man-Machine Studies, 1981, $15,87-134$.

Benbasat, I., Dexter, A. S., \& Masulis, P. S. An experimental study of the human/computer interface. Communications of the ACM, 1981, 24, 752-762.

BENNETT, J. L. The commercial impact of usability in interactive systems, In Infotech State of the Art Report, Man/computer communication (Vol. 2). Maidenhead, England: Infotech International, 1979.

Buxton, W. A. S., \& Sniderman, R. Iteration in the design of the human-computer interface. In Proceedings of the 13th Annual Meeting of the Human Factors Association of Canada. Toronto: Human Factors Association, 1980.

Campeell, D. T., \& Stanley, J. C. Experimental and quasiexperimental designs for research. Chicago: Rand McNally, 1963.

Card, S. K., Moran, T. P., \& Newell, A. Computer textediting: An information-processing analysis of a routine cognitive skill. Cognitive Psychology, 1980, 12, 32-74.

Chapanis, A. Words, words, words. Human Factors, 1965, 7, $1-17$.

Cook, T. D., \& CAmpbell, D. T. Quasi-experimentation. Design and analysis issues for field settings. Chicago: Rand McNally, 1979.

Denzin, N. K. The research act. New York: McGraw-Hill, 1978.

Dillon, R. F., \& Tombauah, J. W. Psychological research on videotex. Behavior Research Methods \& Instrumentation, 1982, 14, 191-197.

Ericsson, K. A., \& Simon, H. A. Verbal reports as data. Psychological Review, 1980, 87, 215-251.

Feldman, M., \& Rogers, G. Toward the design and development of style-independent interactive systems. In Proceedings of Human Factors in Computer Systems. Washington, D.C: Association for Computing Machinery, 1982.

Green, M. Towards a user interface prototyping system. In Proceedings of Graphics Interface '82. Toronto: National Computer Graphics Association of Canada, 1982.

Johnson, E. M., \& BAKER, J. D. Field testing: The delicate compromise. Human Factors, 1974, 16, 203-214.
LEWIS, C., \& MACK, R. Learning to use a text processing system: Evidence from "thinking aloud" protocols. In Proceedings of Human Factors in Computer Systems. Washington, D.C: Association for Computing Machinery, 1982.

Macdonald-Ross, M. Graphics in texts. In L. Shulman (Ed.), Review of research in education (Vol. 5). Itasca, Ill: Peacock, 1978.

Marcel, T., \& Barnard, P. Paragraphs of pictographs. The use of non-verbal instructions for equipment. In P. Kolers, $M$. Wrolstad, \& H. Bouma (Eds.), Processing of visible language (Vol. 1). New York: Plenum, 1979.

MARX, M. H., \& Hillix, W. A. Systems and theories in psychology. New York: McGraw-Hill, 1963.

MAYER, R. E. The psychology of how novices learn computer programming. Computing Surveys, 1981, 13, 121-141.

McConkie, G. W. Learning from text. In L. Shulman (Ed.), Review of research in education. Itasca, Ill: Peacock, 1978.

Moher, T., \& Schneider, G. M. Methodology and experimental research in software engineering. International Journal of ManMachine Studies, 1982, 16, 65-87.

Moran, T. P. An applied psychology of the user. Computing Surveys, 1981, 13, 1-11. (a)

Moran, T. P. The command language grammar: A representation for the user interface of interactive computer systems. International Journal of Man-Machine Studies, 1981, 15, 3-50. (b)

Norman, D. Steps toward a cognitive engineering: Design rules based on analysis of human error. In Proceedings of Human Factors in Computer Systems. Washington, D.C: Association for Computing Machinery, 1982.

Patton, M. Q. Qualitative evaluation methods. Beverly Hills: Sage, 1980.

RAMSEY, H. R., \& ATwood, M. E. Human factors in computer systems: $A$ review of the literature. Englewood, Col: Science Applications, 1979.

RENNIE, A. M. The application of ergonomics to consumer product evaluation. Applied Ergonomics, 1981, 12, 163-168.

Roach, J., Hartson, H. R., Ehrich, R., Yunten, T., \& Johnson, D. DMS: A comprehensive system for managing human-computer dialogue. In Proceedings of Human Factors in Computer Systems. Washington, D.C: Association for Computing Machinery, 1982.

Rutman, L. Planning useful evaluations. Evaluability assessment. Beverly Hills: Sage, 1980.

Sanders, J., \& Cunningham, D. A structure for formative evaluation in product development. Review of Educational Research, 1973, 43, 217-236.

Sebrechts, M. M., Deck, J. G., \& Bl.ack, J. B. A diagrammatic approach to computer instruction for the naive user. Behavior Research Methods \& Instrumentation, 1983, 15, 200-207.

Thompson, C. W. N., \& RAth, G. J. The administrative experiment: A special case of field testing or evaluation. Human Factors, 1974, 16, 238-252.

WAGNER, C. Quality control methods for IBM computer manuals. Journal of Technical Writing and Communication, 1980, 10, 93-102.

Wholey, J. S. Evaluability assessment. In L. Rutman (Ed.), Evaluation research methods: $A$ basic guide. Beverly Hills: Sage, 1977.

Winbush, B., \& McDowell, G. Testing: How to increase the usability of computer manuals. Technical Communication. $1980,4,20-22$.

WRIGHT, P. Feeding the information eaters: Suggestions for integrating pure and applied research on language comprehension. Instructional Science, 1978, 7, 249-312. 